\title{
Global Engineering Design Symposium: Engaging the Sociocultural Dimen- sions of Engineering Problem Solving
}

\section{Prof. Brent K Jesiek, Purdue University, West Lafayette}

Dr. Brent K. Jesiek is assistant professor in the Schools of Engineering Education and Electrical and Computer Engineering at Purdue University. He is also an associate director of Purdue's Global Engineering Program and leads the Global Engineering Education Collaboratory (GEEC) research group. He holds a B.S. in Electrical Engineering from Michigan Tech and M.S. and Ph.D. degrees in Science and Technology Studies (STS) from Virginia Tech. Dr. Jesiek draws on expertise from engineering, computing, and the social sciences to advance understanding of geographic, disciplinary, and historical variations in engineering education and professional practice.

\section{Miss Anne Elizabeth Dare, Purdue University}

Anne Dare is a Ph.D. student in the Department of Agricultural \& Biological Engineering at Purdue University, and holds a joint appointment with the Global Engineering Program (GEP) as its Global Design Team Coordinator. She received her B.S. in 2008 and M.S.E. in 2010 from Purdue University and was a member of GEP's pilot Global Design Team. As an undergraduate, Dare spent several summers working with the USDA Natural Resources Conservation Service as an Agricultural Engineer Trainee. Dare's M.S.E. thesis involved developing a model of the attributes that define an engineer's global competence and assessing those attributes in students participating in international experiences, including Global Design Teams. In her Ph.D. work, Dare will focus her dissertation on the limitations of treated wastewater reuse in agriculture from the perspectives of technology, policy, and public perception with case studies in Qatar, Tunisia, Palestinian West Bank, and United States.

\section{Ms. Julia D Thompson, Purdue University, West Lafayette \\ Mr. Tiago R Forin, Purdue University, West Lafayette}

Tiago Forin is currently a student in the School of Engineering Education at Purdue University. He received his bachelor's degree in Civil Engineering from Florida State University in 2006 and his master's degree in Environmental Engineering from Purdue University in 2008. While in the School of Engineering Education, he works as a graduate research assistant in the X-Roads Research Group and has an interest in cross-disciplinary practice and engineering identity development. 


\title{
Global Engineering Design Symposium: Engaging the Sociocultural Dimensions of Engineering Problem Solving
}

\begin{abstract}
Global service-learning continues to gain prominence in many engineering schools. At Purdue University, for example, three main programs offer students global engineering project experience in the context of international development, namely Engineers Without Borders (EWB), Global Design Teams (GDTs), and Engineering Projects in Community Service (EPICS). Participating students work to create technical solutions to address community needs, either for academic credit or as an extracurricular activity. Students involved with such projects typically have ready access to the technical resources and expertise needed to carry out their work, including support from participating faculty and staff. However, preparing students for the non-technical aspects of their projects is often more difficult since it requires that they learn how to identify and grapple with the kinds of social, cultural, and political considerations that frequently emerge when working on real-world problems in developing contexts.
\end{abstract}

To address these challenges, Purdue's Global Engineering Program (GEP) organized Global Engineering Design Symposium (GEDS) events in 2012 and 2013. Each half-day symposia attracted more than 90 students, faculty, and staff, and featured presentations, panels, and interactive exercises covering topics such as global competency, transdisciplinary teamwork, human-centered design, and stakeholder/needs analysis. This paper offers a detailed description of symposia. We also report pre- and post-event assessment data from participating students, including: 1) demographics, 2) results from Political and Social Involvement Scale (PSIS) survey questions, 3) Cultural Intelligence (CQ), 4) quantitative evaluation scores for all major event components, and 5) qualitative results from three open-ended event evaluation questions.

The major goals of this paper include: characterizing the engineering students who opt into these kinds of programs, providing faculty and staff at other institutions with inspiration and guidance for organizing similar kinds of training opportunities, and exploring strategies for systematically assessing the effectiveness of such events. This work is important as part of ongoing efforts to explore how engineering curricula can be expanded to address a wider range of technical, professional, and global competencies, while allowing students and faculty to make a positive change in the world. In summary, the events were viewed very favorably by most students, with many specifically noting the value of hearing about specific stories and cases from the speakers and being challenged to think about what it means to identify and address community needs in different cultural contexts. Additionally, we find considerable evidence of self-selection factors among students participating in these programs and events. 


\section{Introduction}

Against the backdrop of globalization trends, intensified discourses around global "grand challenges," and persistent calls for engineering education reform, global service-learning is gaining prominence at many engineering schools. A handful of integrated curricular programs with long histories, such as Worcester Polytechnic Institute's Global Perspective Program (GPP), continue to grow and set high standards for international project work. ${ }^{1}$ Other pioneering programs, such as Engineering Projects in Community Service (EPICS) at Purdue University, are expanding their global project portfolios. ${ }^{2}$ Many other schools have undertaken their own new initiatives, such as the Humanitarian Engineering program at Colorado School of Mines (CSM) and Engineering for Developing Communities Program at UC-Boulder. ${ }^{3-4}$ Engineers Without Borders (EWB) has also grown rapidly since its founding in 2002, most often as either an extracurricular activity for students or volunteer activity for faculty and professionals. EWB now has chapters at more than 180 schools in the United States, and a growing global footprint. ${ }^{5}$

Nonetheless, preparing faculty, staff, and students to undertake successful and effective project work - while also supporting student learning - is no trivial task, especially when engaging with partners and communities in developing contexts. As a growing body of literature suggests, the associated challenges are manifold and formidable. To name a few, they include: working through language and cultural differences; anticipating the possible unintended consequences of proposed design solutions; acknowledging and learning from failures; recognizing how project work intersects with issues of social justice and inequality; and systematically assessing impacts on all relevant stakeholders, including students, partners, community members, etc. ${ }^{6-7}$ More generally, addressing such issues often demands that faculty and students meaningfully engage with the full spectrum of social, cultural, and political considerations that necessarily emerge when working on real-world problems. Yet despite considerable passion and enthusiasm, many participants lack the training and experience needed to proactively deal with these kinds of issues, which in turn inhibits their ability to truly serve their community partners.

To begin addressing these challenges, Purdue's Global Engineering Program (GEP) organized its first annual Global Engineering Design Symposium (GEDS) events in January 2012 and 2013. These half-day events attracted more than 90 students, faculty, and staff from three engineering service-learning programs, and featured presentations, panels, and interactive exercises covering topics such as global competency, transdisciplinary teamwork, human-centered design, and stakeholder/needs analysis. This paper offers a detailed description of the two symposia, as well as a summary of pre- and post-event assessment and evaluation data collected from participating students. As further background, the literature review that follows discusses other ongoing efforts to improve how students and faculty are readied for global project work. The goals of this paper include providing faculty and staff at other institutions with inspiration and guidance for organizing similar kinds of training opportunities, characterizing the engineering students who opt into global service-learning programs, and exploring strategies for assessing such events.

\section{Preparing Engineers for Global Service-Learning: Resources and Strategies}

While many global service-learning programs and initiatives provide training opportunities for students, there has been little in the way of coherent discourse or discussion around the topic. 
Some materials, models, and strategies are available, but they remain largely scattered and disconnected, and there has been a lack of systematic research evaluating their effectiveness. While a comprehensive review is not possible here, we share a few important touchstones.

To begin, a handful of extant resources are specifically designed to help prepare engineering students for community project work, including in global context. For example, Lucena, Schneider, and Leyden's Engineering and Sustainable Community Development is intended as a textbook for students who are preparing to work with communities. ${ }^{8}$ Major topics include the history of engineering and development, reasons why traditional approaches to engineering design often fail when working with communities, and strategies for overcoming these obstacles. The book emphasizes the importance of listening to community members, and for instructional purposes offers numerous case studies and poses many reflection and discussion questions. Mihelcic et al.'s Field Guide to Environmental Engineering for Development Workers: Water, Sanitation, and Indoor Air similarly emphasizes community participation. ${ }^{9}$ Yet it is somewhat more specifically scoped as an environmental engineering field guide, with extensive technical discussion of appropriate technologies for water supply and treatment, latrine building, sanitation, etc. The design firm IDEO, on the other hand, has developed a Human Centered Design Toolkit, which is organized around processes, methods, and tools that can be used to identify problems and design solutions for communities in need. ${ }^{10}$ It is available as a free e-book, and includes many tips, case studies, and worksheets, along with a field guide.

Engineering for Change (E4C) is another relevant resource for technical professionals who are addressing humanitarian problems, particularly in developing contexts. ${ }^{11-12}$ Jointly founded by ASME, IEEE, and EWB in 2011, this emergent online community hosts a growing range of resources, including: lists of design principles; links to relevant academic programs, publication outlets, and online training; hub pages for specific interest areas (e.g., water, energy, health, etc.); and tools for sharing information about project and partnerships opportunities, solution case studies, etc. Also notable is the organization's monthly webinar series, which by April of 2013 featured an archive of 28 presentations on topics ranging from housing and human rights to ICTs and electrification. Still other initiatives are explicitly emphasizing the need to evaluate, predict, and candidly share the full range of impacts that projects have on partner communities, including both positive and negative outcomes. At the forefront of this movement are organizations like Engineers Without Borders (EWB) Canada, which has published its annual Failure Report since 2008 and has developed an accompanying Admitting Failure web site and database. ${ }^{13-14}$

More formal training opportunities, including courses, certificates, and degrees are offered at a small but growing number of institutions. Notable examples at the undergraduate level include Colorado School of Mines, with certificate and minor programs in Humanitarian Engineering, and related coursework such as a 3-credit offering on Engineering and Sustainable Community Development. Sixteen thematic courses are offered by MIT's D-Lab, all organized around an overarching mission of supporting "development through dialogue, design and dissemination." 15 WPI prepares GPP students for project work abroad through a required course on social science research methods, while Penn State offers a 1-credit Design for Developing Communities course as part of its Humanitarian Engineering and Social Entrepreneurship (HESE) program. ${ }^{16-17}$ And at University of Dayton, a 3-credit course on Engineering Design and Appropriate Technology helps prepare students for international service-learning, including through coverage of topics 
like foreign language fundamentals, appropriate technology, and cultural immersion. ${ }^{18}$ Still other schools (e.g., UC Boulder, Columbia University, and Michigan Tech) offer graduate-level certificates and/or degree programs at the intersection of engineering and development.

Other related initiatives include the NSF-supported Engineering Faculty Engagement in Learning Through Service (EFELTS) project, which is mainly focused on preparing faculty to organize and lead high-impact service-learning experiences at home and abroad, including through faculty development workshops. ${ }^{19}$ Engineers Without Borders also has a record of providing training opportunities to students and faculty, most notably through regional and national conferences, and more recently through efforts to create a more comprehensive set of online training materials for EWB students and professionals. As noted below, our own efforts to develop an annual symposium series is similar to these other efforts since it is designed to attract a wide variety of participants and runs as an optional or extracurricular activity. Before discussing the symposium in more detail, however, we offer a more detailed description of the programs and populations it is designed to serve.

\section{Program Descriptions}

Purdue's most prominent service-learning program is Engineering Projects in Community Service (EPICS). EPICS project teams typically consist of engineering students from various degree programs (although non-engineering majors participate as well), from first-year to senior status. Project partners include domestic and international not-for-profit organizations, schools, and other departments within Purdue University. The partners submit project ideas, and objectives are developed through close collaboration between the partners and project teams. Projects may last several semesters, during which time team members may change as students graduate or elect to leave the program. EPICS utilizes a vertically-integrated project team model which allows for continuity between semesters. ${ }^{20}$ During 2011-2012, more than 600 students participated in an EPICS project, with over 200 students typically returning semester-tosemester, and about 90 involved with global projects. All students in EPICS are enrolled for academic credit. The EPICS model was founded at Purdue in 1995, and has been adopted by more than twenty universities in the United States, Columbia, Puerto Rico, and New Zealand.

Engineers Without Borders (EWB) is another engineering service-learning program with 180 chapters in the United States and 250 chapters worldwide. ${ }^{5}$ Purdue's EWB chapter operates as a student organization, offering no academic credit for participating students. Staff at EWB headquarters pair student groups with host communities and non-governmental organizations to address infrastructure and resource issues in developing countries. EWB's model promotes community ownership of projects, and encourages consideration of social, economic, and environmental factors in order to promote sustainability. Student groups may visit their host community from one week up to several months, depending on the circumstances. EWB has set forth three criteria for attributes they expect designs and solutions to exhibit: ability to be replicated in neighboring communities, easy to maintain, and use of appropriate technologies. ${ }^{21}$

Purdue's Global Design Team (GDT) model brings together undergraduate and graduate students from different disciplines, inside and outside of engineering, to solve real-world problems in collaboration with international partner organizations. ${ }^{22}$ The projects are identified 
by community organizations, businesses, or other research institutions, and students are recruited to work closely with end users to accomplish three primary goals: 1) provide students with realworld, full-cycle design experiences, 2) raise the global awareness of students through global experiences, and 3) increase global humanitarian impact. Depending on the size and scope of a given project, teams may range from two to twenty students, typically under the guidance of one faculty member. The most intensive period of GDT activity is Spring semester, with recruitment and planning the main focus during Summer and Fall. Students who travel in support of GDT projects typically do so during spring or summer. Starting with one project and five students in 2008, the program has grown to eight projects and 81 students in 2012-13.

The GDT model fills current gaps in international service-learning by providing students with projects that are relevant to their degree program and personal interests, and are complementary to their program's curriculum. All GDT students enroll for academic credit and are assessed based on course contracts made with their faculty advisor. Through academic accountability and a program staff committed to maintaining and growing relationships with partner communities, the GDT model encourages the building of a knowledge base, sets high expectations for project quality, and promotes long-term partnerships. The projects are designed to provide mutual benefit through learning and service experiences for students and added value to international partners. Yet the distributed nature of GDTs also poses challenges, including variation in the extent to which participating students are prepared to address problems in developing contexts.

\section{Symposium Description}

Responding to requests by students, faculty, and staff to provide more training and events for students involved in Global Design Teams, the concept of a half-day design symposium was put forward. To maximize the benefit of coordinating such an event and provide cross-program interaction and cross-fertilization for participants, invitations were also sent to students and staff affiliated with the Global EPICS program and Purdue's EWB student chapter. The inaugural Global Engineering Design Symposium (GEDS) held on Saturday, January 21, 2012, and the second annual event on January 26, 2013. The events were scheduled early in the semester so students would be familiar with their projects, but in a position to benefit from the symposium.

Through presentations, panels, and interactive exercises, the 4-5 hour symposia programs covered topics like global competency, transdisciplinary teamwork, human-centered design, and stakeholder/needs analysis. Presentations were provided by internal faculty and invited speakers with backgrounds in engineering, engineering education, environmental science, anthropology, science and technology studies, and international development. During both years, panels were convened with students and recent alum who had been involved with international development projects and international research so that students could hear first-hand about the successes and challenges of such projects and pose questions to the panelists. Additionally, interactive exercises using case studies from international development failures allowed students to reflect on some of the factors that can contribute to unsuccessful projects, while challenging them to relate those factors to their own projects. A summary of each GEDS schedule is presented below, in Tables 1 and 2. More information, including slides and videos from select presentations, can be found on the GlobalHUB online cybercommunity. ${ }^{23}$ 
Table 1. 2012 Global Engineering Design Symposium (GEDS) Schedule

\begin{tabular}{|c|c|}
\hline Est. Time & Presentation or Activity \\
\hline $15 \mathrm{~min}$ & Welcome, introductions, and pre-symposium survey \\
\hline $15 \mathrm{~min}$ & Opening Reflection Question: What is the difference between "service" and "development"? \\
\hline $40 \mathrm{~min}$ & $\begin{array}{l}\text { Global Competency: Problem Solving with People } \\
\text { Prof. Brent Jesiek, School of Engineering Education, Purdue University }\end{array}$ \\
\hline $40 \mathrm{~min}$ & $\begin{array}{l}\text { Working Across Disciplines: Easier Said Than Done } \\
\text { Prof. Riall Nolan, Department of Anthropology, Purdue University }\end{array}$ \\
\hline $40 \mathrm{~min}$ & $\begin{array}{l}\text { Seeing Social Power: Technology Design for User Empowerment } \\
\text { Prof. Dean Nieusma, Science and Technology Studies, Rensselaer Polytechnic Institute }\end{array}$ \\
\hline $30 \mathrm{~min}$ & Lunch \\
\hline $30 \mathrm{~min}$ & $\begin{array}{l}\text { Case Study Breakout Session and Facilitated Discussions } \\
\text { - Get a Pig, Pay Two Piglets } \\
\text { - One Thing Leads to Another: Steel Axes and Social Change }{ }^{25} \\
\text { - The Stranger's Eyes } \\
\text { - Thrown Out on the Edge of Asia }{ }^{27}\end{array}$ \\
\hline $45 \mathrm{~min}$ & $\begin{array}{l}\text { Global Service-Learning - Student and Professional Project Panel } \\
\text { - Being a Good International Partner: A Few Lessons Learned (and Observed) from } \\
\text { International Projects } \\
\text { Anne Dare, GEP and Agricultural and Biological Engineering, Purdue University } \\
\text { - Global Engineer: Frames } \\
\text { Tiago Forin, School of Engineering Education, Purdue University } \\
\text { - Useful Knowledge for Design Solutions } \\
\text { - Lindsey Payne, Department of Earth and Atmospheric Sciences, Purdue University } \\
\text { EWB Kenya Water Project } \\
\text { Emily Wigley, EWB Chicago Professional Chapter }\end{array}$ \\
\hline $30 \mathrm{~min}$ & $\begin{array}{l}\text { Final Team Breakouts } \\
\text { - What did you learn today? What were some of the most significant themes? } \\
\text { - Which topics, tools, themes, etc. are most relevant to your project? } \\
\text { - What specific things will you try to do this semester as a result of participating in this meeting? }\end{array}$ \\
\hline $15 \mathrm{~min}$ & Symposium closing, debrief, and post-symposium evaluation survey \\
\hline
\end{tabular}

Table 2. 2013 Global Engineering Design Symposium (GEDS) Schedule

\begin{tabular}{|ll|}
\hline Est. Time & Presentation or Activity \\
\hline $15 \mathrm{~min}$ & Introduction, framing, surveys \\
$45 \mathrm{~min}$ & Hello... I'm Here to Save the World... \\
& $\begin{array}{l}\text { Robert Swap, Research Associate Professor, Department of Environmental Sciences, University } \\
\text { of Virginia }\end{array}$ \\
& Global service learning panel \\
& - \\
& Karibu \\
& Peter Caldwell, World Help Solutions, Inc. and Landscape Architecture, Purdue University \\
& Spring Boxes: Bungoma, Kenya \\
& Jenna McGregor, Engineers Without Borders USA, Indianapolis Professional Chapter \\
& Global Understanding through EPICS Program \\
& Sarah Paulsen, EPICS and Construction Engineering Management, Purdue University \\
& Educational Concerns for Hunger Organization (ECHO) Asia Regional Impact Center Seed \\
& Bank \\
\hline
\end{tabular}




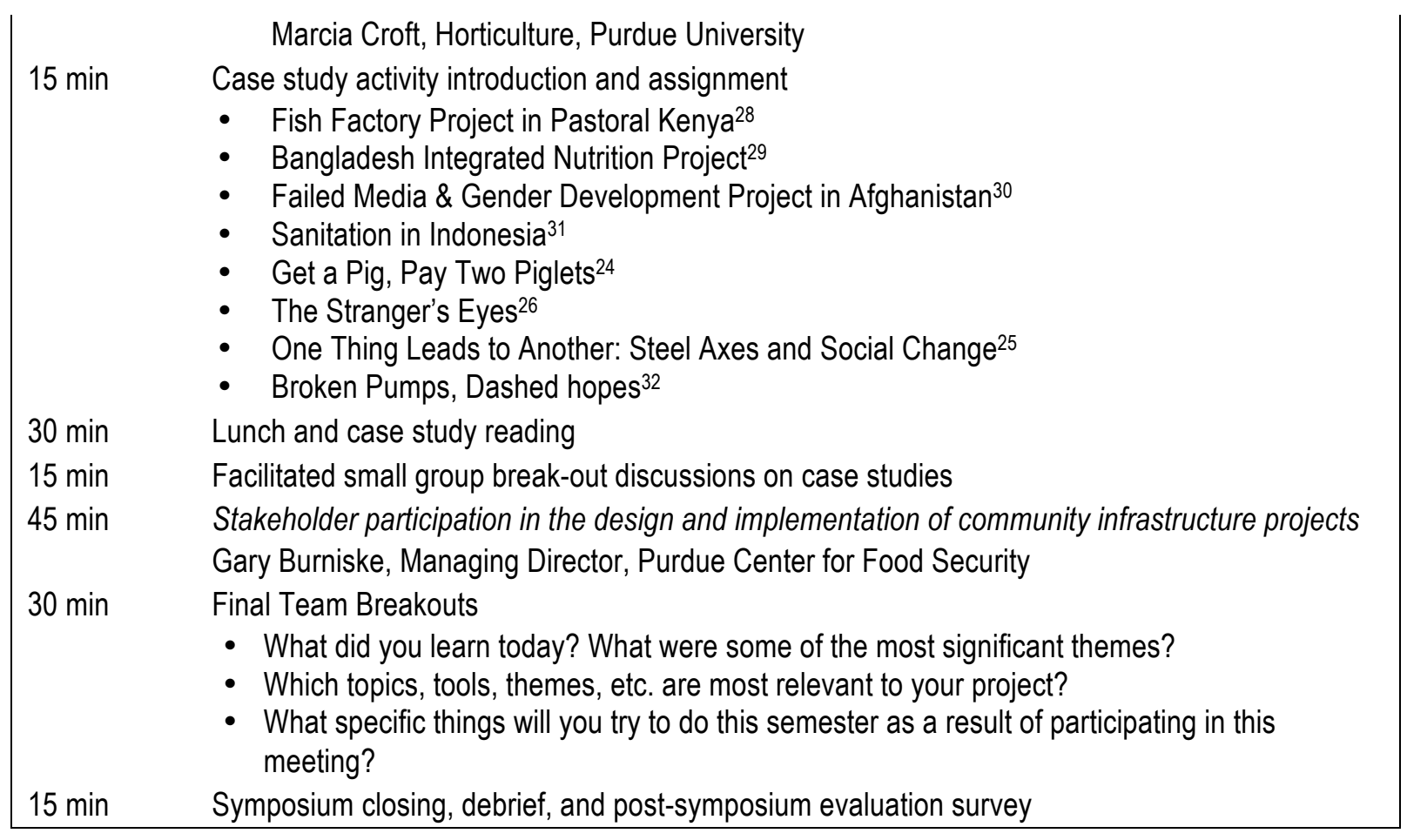

\section{Participant Characteristics}

\section{Demographics}

Table 3 summarizes demographic characteristics for Purdue students who both registered to attend a GEDS event and completed all survey procedures. As indicated, representatives of the EPICS and GDT programs comprised the large majority of participants. During both events, engineering students were predominant, although a handful of other disciplines were also represented. First-year and senior level students were predominant in 2012, which may in part reflect a more general pattern of gravitation toward design and project work at the "bookends" of the typical engineering curricula, while core engineering science classes and technical electives dominate the sophomore and junior years. ${ }^{33}$ Following broader trends reported in the literature, we also observe much larger numbers of women participants as compared to relevant baseline populations (e.g., about $22 \%$ of engineering students at Purdue were female in 2012), with in an equal gender balance among respondents in 2012 and more than 40\% women attending in 2013. ${ }^{34}$ Representation of underrepresented minority groups and international students appear roughly comparable to the broader student population in the College of Engineering. 
Table 3. Summary of Participant Demographics

\begin{tabular}{|c|c|c|c|c|c|}
\hline & $\begin{array}{c}2012 \\
\text { GEDS } \\
(\mathrm{n}=80)\end{array}$ & $\begin{array}{c}2013 \\
\text { GEDS } \\
(n=69)\end{array}$ & & $\begin{array}{l}2012 \\
\text { GEDS } \\
(\mathrm{n}=80)\end{array}$ & $\begin{array}{c}2013 \\
\text { GEDS } \\
(n=69)\end{array}$ \\
\hline Degree program & & & Program affiliation & & \\
\hline Engineering & 67 & 66 & Global Design Teams (GDT) & 30 & 28 \\
\hline First-Year Engineering* & 18 & 9 & Global EPICS & 41 & 36 \\
\hline $\begin{array}{l}\text { Agricultural \& Biological } \\
\text { Engineering }\end{array}$ & 8 & 21 & $\begin{array}{l}\text { Engineers Without Borders } \\
\text { (EWB) }\end{array}$ & 9 & 5 \\
\hline Chemical Engineering & 4 & 4 & & & \\
\hline Civil Engineering & 7 & 4 & Academic level & & \\
\hline Construction Engineering \& & 1 & 1 & First-year & 25 & 20 \\
\hline Management & & & Sophomore & 14 & 16 \\
\hline Electrical Engineering & 3 & 6 & Junior & 8 & 13 \\
\hline Engineering Education & 2 & 0 & Senior & 24 & 17 \\
\hline $\begin{array}{l}\text { Environmental \& Ecological } \\
\text { Enqineering }\end{array}$ & 9 & 2 & Graduate (MS or PhD) & 8 & 3 \\
\hline Industrial Engineering & 3 & 0 & & & \\
\hline Materials Engineering & 2 & 1 & Gender & & \\
\hline Mechanical Engineering & 9 & 9 & Female & 40 & 28 \\
\hline Multi/Interdisciplinary Eng. & 1 & 1 & Male & 40 & 40 \\
\hline Aeronautics and & 0 & 3 & & & \\
\hline Astronautics Engineering & 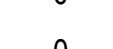 & 5 & Ethnicity & 0 & 10 \\
\hline $\begin{array}{l}\text { Blomedical Engıneering } \\
\text { Science }\end{array}$ & 5 & 3 & Black or African American & 20 & 10 \\
\hline & 1 & 0 & Hispanic or Latino & 4 & 7 \\
\hline Biochemistry & 1 & 0 & White or Caucasian & 51 & 46 \\
\hline Biological Sciences & 2 & 0 & Multiracial & 3 & 2 \\
\hline Pharmaceutical Sciences & 1 & 3 & Other & 1 & 1 \\
\hline Technology & 6 & 3 & & & \\
\hline Industrial Design & 1 & 1 & International Student? & & \\
\hline Mechanical Engineering & 2 & 1 & Yes & 19 & 16 \\
\hline Technology & 2 & 1 & No & 61 & 53 \\
\hline $\begin{array}{l}\text { Organizational and } \\
\text { Leadership Supervision }\end{array}$ & 1 & 0 & & & \\
\hline $\begin{array}{l}\text { Sustainability, Innovation, } \\
\text { and Technology }\end{array}$ & 0 & 1 & & & \\
\hline Not specified & 2 & 0 & & & \\
\hline Other & 2 & 0 & & & \\
\hline Communications & 1 & 0 & & & \\
\hline Undecided & 1 & 0 & & & \\
\hline
\end{tabular}

\section{Political and Social Involvement Scale (PSIS)}

Students were also asked to complete the Political and Social Involvement Scale, adapted near verbatim from the Wabash National Study of Liberal Arts Education. ${ }^{35}$ Respondents were asked to indicate "how important to you personally" is each statement listed in Table 4, with response options ranging from "Not Important" and "Somewhat Important" to "Very Important" and "Essential." The percentage of students indicating that each given objective is "Very Important" 
or "Essential" is shown in the table. Additionally, results from a 2007 national study of college seniors is indicated as a comparative baseline. ${ }^{36}$ As noted in the table, this study featured two statements with different wording and did not include a spirituality question. Hence, results from a different national study are reported for the spirituality statement. ${ }^{3}$

Table 4. Summary Results for Political and Social Involvement Scale

\begin{tabular}{|c|c|c|c|c|c|}
\hline $\begin{array}{l}\text { Student objectives noted as "Very } \\
\text { Important" or "Essential" }\end{array}$ & $\begin{array}{c}\text { CSS } \\
2007 \\
n=26,710\end{array}$ & $\begin{array}{c}\text { GEDS } \\
2012 \\
n=80\end{array}$ & $\begin{array}{c}\text { Diff b/w } \\
\text { GEDS } \\
2012 \& \\
\text { CSS }\end{array}$ & $\begin{array}{l}\text { GEDS } \\
2013 \\
n=68\end{array}$ & $\begin{array}{c}\text { Diff b/w } \\
\text { GEDS } \\
2013 \& \\
\text { CSS }\end{array}$ \\
\hline (A) Becoming a community leader & $43.6 \%$ & $53.8 \%$ & $+10.2 \%$ & $57.4 \%$ & $+13.8 \%$ \\
\hline $\begin{array}{l}\text { (B) Becoming involved in activities that } \\
\text { preserve and enrich the environment }\end{array}$ & $30.6 \%{ }^{1}$ & $86.3 \%$ & $+55.7 \%$ & $86.8 \%$ & $+56.2 \%$ \\
\hline (C) Helping others who are in difficulty & $78.0 \%$ & $97.5 \%$ & $+19.5 \%$ & $89.7 \%$ & $+11.7 \%$ \\
\hline $\begin{array}{l}\text { (D) Improving my understanding of other } \\
\text { countries and cultures }\end{array}$ & $61.6 \%$ & $82.5 \%$ & $+20.9 \%$ & $80.9 \%$ & $+19.3 \%$ \\
\hline (E) Keeping up to date with political affairs & $50.4 \%$ & $51.3 \%$ & $+0.9 \%$ & $41.2 \%$ & $-9.2 \%$ \\
\hline (F) Developing a meaningful philosophy of life & $58.9 \%$ & $80.0 \%$ & $+21.1 \%$ & $79.4 \%$ & $+20.5 \%$ \\
\hline (G) Helping to promote racial understanding & $41.1 \%$ & $76.3 \%$ & $+35.3 \%$ & $72.1 \%$ & $+31.0 \%$ \\
\hline (H) Influencing social values & $52.6 \%$ & $73.8 \%$ & $+21.2 \%$ & $72.1 \%$ & $+19.5 \%$ \\
\hline (I) Influencing the political structure & $27.0 \%$ & $47.5 \%$ & $+20.5 \%$ & $29.4 \%$ & $+2.4 \%$ \\
\hline (J) Integrating spirituality into my life & $50.4 \%^{2}$ & $60.0 \%$ & $+9.6 \%$ & $58.8 \%$ & $+8.4 \%$ \\
\hline (K) Volunteering in my community & $39.1 \%^{3}$ & $85.0 \%$ & $+45.9 \%$ & $79.4 \%$ & $+40.3 \%$ \\
\hline
\end{tabular}

As compared to the baseline, national sample, GEDS participants scored consistently higher on all statements except (E), which was roughly equal for the 2012 GEDS respondents and nearly 9\% lower for the 2013 GEDS group. As might be expected, the largest differences between the GEDS groups and baseline data are evident in statements most directly relevant to global service-learning activities, including $(\mathrm{B})$ and $(\mathrm{K})$, which focus on environmental and service themes. However, participants also responded strongly to statement $(\mathrm{G})$, which relates to promoting racial understanding. These results provide evidence for high levels of self-selection, with global service-learning programs attracting large numbers of students with strong preexisting political and social commitments. As noted below, this tendency poses both opportunities and challenges related to developing and growing such programs.

\section{Cultural Intelligence}

Finally, all GEDS 2012 survey respondents were asked to complete a Cultural Intelligence (CQ) survey, a 20-item instrument designed to measure "the capability of an individual to function effectively in situations characterized by cultural situation." "38 The questions cover four dimensions, namely: four items covering metacognitive CQ, or "an individual's cultural consciousness and awareness" during cross-cultural interactions; six questions measuring cognitive CQ, or "an individual's cultural knowledge of norms, practices, and conventions" of other cultures; five items for motivational CQ, or "an individual's capability to direct attention 
and energy toward cultural differences"; and five items measuring behavioral CQ, or "an individual's capability to exhibit appropriate verbal and nonverbal actions" in cross-cultural interactions. ${ }^{38}$ One sample question for each CQ dimension is given in Table 5. The CQ scale has been demonstrated to be valid and reliable. ${ }^{38}$ The instrument is a good fit for our evaluation and research efforts because it can be completed quickly, is freely reusable in unmodified form, and measures aspects of cross-cultural competence across four partially distinct dimensions.

Table 5. CQ Dimensions and Sample Survey Questions ${ }^{29}$

\begin{tabular}{|l|l|}
\hline CQ Dimension & Sample Survey Question \\
\hline Metacognitive & I am conscious of the cultural knowledge I apply to cross-cultural interactions \\
\hline Cognitive & I know the arts and crafts of other cultures \\
\hline Motivational & I enjoy interacting with people of different cultures \\
\hline Behavioral & I change my nonverbal behavior when a cross-cultural situation requires it \\
\hline
\end{tabular}

Summary results for the GEDS 2012 participant group are presented in Table 6 (CQ data was not collected for the 2013 group). Of particular interest is the question of whether there are notable differences in average CQ scores between the GEDS respondents and other relevant populations. Our results are readily compared with: 1) data we collected from 142 undergraduate mechanical engineering students, primarily sophomores and juniors, who were enrolled in a required ME seminar course at Purdue University, and 2) Van Dyne et al.'s study of 337 undergraduate students at another large university in the Midwest U.S. ${ }^{38}$

Table 6. Descriptive Statistics for CQ Subscales and Overall, by Subject Group

\begin{tabular}{|c|c|c|c|c|c|c|c|c|c|c|c|}
\hline \multicolumn{2}{|c|}{ CQ Dimension $\rightarrow$} & \multicolumn{2}{|c|}{ Cognitive } & \multicolumn{2}{|c|}{ Metacognitive } & \multicolumn{2}{|c|}{ Behavioral } & \multicolumn{2}{|c|}{ Motivational } & \multicolumn{2}{|c|}{ Overall } \\
\hline Subject Group & $\mathbf{N}$ & M & SD & M & SD & M & SD & M & SD & M & SD \\
\hline GEDS & 80 & 4.40 & 1.53 & 5.52 & 1.10 & 5.26 & 1.17 & 5.86 & 1.04 & 5.20 & 1.37 \\
\hline ME Seminar & 142 & 4.17 & 1.21 & 5.26 & 1.03 & $4.87^{*}$ & 1.06 & $5.25^{\star \star}$ & 1.17 & $4.89^{* *}$ & 0.87 \\
\hline Van Dyne et al. ${ }^{29}$ & 337 & 3.66 & 0.98 & 4.98 & 0.95 & 4.20 & 1.14 & 5.34 & 0.94 & 4.48 & $\mathrm{n} / \mathrm{a}$ \\
\hline
\end{tabular}

${ }^{*}$ Difference between GEDS and ME groups significant $(p<0.5)$ based on Pooled t-test (equal variances)

** Differences between GEDS and ME groups significant $(p<0.5)$ based on Satterthwaite t-test (unequal variances)

As shown, average scores for each CQ subscale, as well as overall CQ, are consistently higher for GEDS respondents as compared to the other two groups. Further statistical analysis indicates that scores for the GEDS subjects were significantly higher than the baseline ME group for behavioral, motivational, and overall CQ. These results suggest that respondents perceive themselves as relatively more capable of being able to "direct energy and attention" toward cultural differences, and adopting appropriate behaviors and interactional patterns (including verbal and non-verbal) in cross-cultural situations. These results also appear largely consistent with the PSIS findings above, which showed that $82.5 \%$ of these same respondents felt that "improving my understanding of other countries and cultures" was personally very important or essential to them, while $76.3 \%$ felt the same about "helping to promote racial understanding."

\section{Program Evaluation Results}

Program evaluation data was collected at the end of the symposium using a one-page survey form. The results help us understand how participants viewed the event, including suggestions 
for improvements and potential areas for future training and seminars. The evaluation form included a set of scaled questions, followed by a series of open-ended prompts. Participants were first asked to rate the overall quality of each major symposium presentation/activity on a scale from 1 to 5 (Poor, Fair, Good, Very Good, and Excellent). In the open-ended section, participants were asked to elaborate on: the most positive/beneficial part of the symposium, possible changes/improvements for the symposium, suggestions for other seminars/trainings, and other comments. A total of 71 usable survey responses were collected for the 2012 event, and Excel and Dedoose were respectively used to record and analyze the quantitative and qualitative survey results. All written responses to the open-ended survey questions were transcribed, and an open coding method was utilized to find common themes mentioned by the respondents.

Table 7 gives average scores for each of the presentations/activities, as well as a score for the overall quality of the event and number of respondents who explicitly identified each part of the program as the most beneficial part of the event. The number of responses for each item ranged from 69-71, as two forms were incomplete. As indicated, average responses for each part of the symposium, as well as the event overall, fell in the Good to Excellent range (3-5).

Table 7. Summary of GEDS 2012 Program Evaluation Survey Results (n=71 max)

\begin{tabular}{|l|c|c|c|}
\hline Presentation/Activity (Sequential Order) & $\mathbf{n}$ & $\begin{array}{c}\text { Avg. } \\
\text { Score } \\
(\mathbf{1 - 5})\end{array}$ & $\begin{array}{c}\text { No. indicating } \\
\text { most beneficial } \\
\text { part of program }\end{array}$ \\
\hline Working Across Disciplines (Presentation) & 69 & 4.3 & 7 \\
\hline Global Competency (Presentation) & 69 & 4.87 & 4 \\
\hline Case Study Activity & 71 & 3.62 & 2 \\
\hline Seeing Social Power (Presentation) & 71 & 3.69 & 1 \\
\hline Global Service-Learning Panel & 71 & 4.15 & 5 \\
\hline Final Group Breakout Activity & 69 & 4.09 & 4 \\
\hline Overall Quality of Event & 69 & 3.98 & n/a \\
\hline
\end{tabular}

The open-ended survey responses provide a further window onto those aspects of the symposium viewed as most beneficial for participants. Items identified as most useful were: personal stories and examples $(n=11)$, learning about and understanding the importance of working in the midst of multiple perspectives and viewpoints $(n=10)$, improving the design process $(n=10)$, learning about culture $(n=9)$, and focusing on users when doing project work $(n=6)$. The program evaluation data also reveals many specific opportunities for improving the event. Changes mentioned most often included: more team/group activities $(n=13)$, shorten the duration of the event $(n=12)$, and make the event more interactive $(n=10)$. Other notable suggestions were related to: focusing more on individual projects $(n=7)$, improving the case study exercise $(n=7)$, encourage more sharing of ideas among teams $(n=5)$, and providing more stories and examples $(n=4)$. Finally, many respondents made suggestions for follow-up instruction, including training or support focused on specific technological and/or cultural dimensions of their projects $(n=15)$, continuing instruction on culture more generally $(\mathrm{n}=14)$, and further support on communication challenges, processes, skills, etc. $(n=6)$.

The evaluation results were used to evolve and improve the 2013 event, as described in more detail above. The most notable changes included shortening the duration of the even by a half hour, and organizing a more diverse project panel consisting of two undergraduate students, a 
graduate student, and an EWB professional chapter member. As indicated in Table 8, the program evaluation marks are generally comparable to the 2012 results, with the overall quality of the event again receiving an average score of 4.0, and results from specific event components ranging from 3.7 to 4.6. The most common suggestions for improvement included, in roughly decreasing order of prevalence: more opportunities for discussion and interaction both within and across teams, improve event time management (i.e., start and end on time, stay on schedule), and build more variety into the schedule in terms of types of presenters, topics, and projects. Two participants also suggested that for future events we invite members of developing communities to share their perspectives on what it means to be local partners on global service projects.

Table 8. Summary of GEDS 2013 Program Evaluation Survey Results (n=56 max)

\begin{tabular}{|l|c|c|c|}
\hline Presentation/Activity (Sequential Order) & Avg. & $\begin{array}{c}\text { No. indicating } \\
\text { Score } \\
\text { most beneficial } \\
\text { part of program }\end{array}$ \\
\hline Hello... I'm Here to Save the World... (Presentation) & 56 & 4.6 & 6 \\
\hline Global Engineering Project Panel & 56 & 3.8 & 1 \\
\hline Case Study Activity & 55 & 3.7 & 3 \\
\hline Stakeholder participation (Presentation) & 54 & 4.0 & 4 \\
\hline Final Group Breakout Activity & 36 & 3.4 & 1 \\
\hline Overall Quality of Event & 56 & 4.0 & n/a \\
\hline
\end{tabular}

\section{Conclusion}

We hope this description of our first two GEDS events provides ideas and inspiration for our colleagues who organize similar kinds of workshops or training programs. More specifically, we have tried to provide an overview of the types of resources, activities, topics, and best practices that can be explored to encourage students, faculty, and staff to better understand and critically reflect on the sociocultural dimensions of global service-learning. Additionally, it is hoped that our efforts to collect and share information about the event participants and program evaluation results can benefit others, whether through design and implementation of similar data collection procedures, and/or through comparison of results with the findings presented here.

Feedback collected from GEDS participants is also being used to improve administration of our Global Design Teams. In addition to a pre-departure orientation/training session that is strongly recommended for all students traveling in support of GDT project work, we have organized a Fall orientation meeting so that students get familiar with GDT processes, procedures, and expectations before their Spring semester project work officially begins. In order to promote reflective learning throughout the semester, an expectation has also been set that all GDT students maintain a reflective practice journal. And in the EPICS program, an optional two-hour skill session was developed on the topic "Partnering with Developing Countries." Finally, we will apply what we have learned to continuously improve future GEDS events, which we expect to continue organizing on an annual basis. Of particular note, we continue to explore ways to building more hands-on activities and interaction into future symposia, especially to enhance student learning and engagement. 
The results presented here also point to some larger dynamics and issues related to global service-learning in engineering. For example, growing evidence of self-selection factors pose opportunities in terms of recruiting and retaining gender- and ethnic-diverse populations of engineering students. However, we also observe that the kinds of programs served by our GEDS event attract a somewhat atypical population of engineering students, especially in terms of gender balance, commitments to political and social engagement, and attitudes toward culture and diversity. As our CQ data suggests, these students also perceive themselves as relatively more motivated to engage in cross-cultural interactions, and more behaviorally adept when in such situations. As a consequence, global service-learning programs may have difficulties scaling up, particularly in trying to recruit larger numbers of students whose political, social, and/or cultural outlooks remain comparatively underdeveloped, and whose participation in such programs might prove to be even more profoundly transformative. Ultimately, we may need to think creatively about how to prepare much larger numbers of engineering students and other future technical professionals to understand the sociocultural dimensions of their work and to respond to community needs at home and abroad, regardless of whether they assume roles in NGOs, academic institutions, governments, or corporations, or even simply as engaged citizens.

\section{Acknowledgments}

We gratefully acknowledge the many staff and volunteers from the Global Engineering Program (GEP) and Global Engineering Education Collaboratory (GEEC) who worked behind the scenes to make both symposia successful, as well as the leaders who provided the financial support needed to make the events happen. We also thank the invited speakers and event participants for their willingness to join us in exploring how we can better serve developing communities. 


\section{References}

1. Durgin, W. W., and Zwiep, D. N. Global Projects Prepare WPI Students for the 21st Century. In Weichert, D., Rauhut, D., and Schmidt, R. (Eds.), Educating the Engineer for the 21st Century: Proceedings of the 3rd Workshop on Global Engineering Education, Aachen, Germany, October 1, 2000 (307-313). Kluwer Academic Publishers, New York, Boston, Dordrecht, London, Moscow. 2001.

2. Huff, J., Abraham, D., Zoltowski, C., and Oakes, W. Adapting Curricular Models for Local Service Learning to International Communities. Proceedings of the 2012 ASEE Annual Conference and Exposition, San Antonio, TX, June 23-26, 2012.

3. Moskal, B. M., Skokan, C., Munoz, D., and Gosink, J. Humanitarian Engineering: Global Impacts and Sustainability of a Curricular Effort. International Journal of Engineering Education, 2008. 24(1): 162-174.

4. Amadei, B., and Sandekian, R. Model of Integrating Humanitarian Development into Engineering Education. Journal of Professional Issues in Engineering Education and Practice, 2010. 136(2): 84-92.

5. Engineers Without Borders (EWB). Our Story. Engineers Without Borders (EWB), Boulder, CO. Available at http://www.ewb-usa.org/about-ewb-usa/our-story

6. Lucena, J., and Schneider, J. Engineers, Development, and Engineering Education: From National to Sustainable Community Development. European Journal of Engineering Education, 2008. 33(3): 247-257.

7. Schneider, J., Lucena, J., and Leydens, J. The Value of Critique in Engineering Service. IEEE Technology and Society Magazine, 2009. 28(4): 42-48.

8. Lucena, J., Schneider, J., and Leydens, J. Engineering and Sustainable Community Development. Synthesis Lectures on Engineers, Technology, and Society. Morgan and Claypool, San Rafael, CA. 2010.

9. Mihelcic, J. R., Fry, L. M., Myre, E. A., Philips, L. D., and Barkdoll, B. D. Field Guide to Environmental Engineering for Development Workers: Water, Sanitation, and Indoor Air. ASCE Press, Reston, VA. 2009.

10. IDEO. Human-Centered Design Toolkit, 2nd Edition. IDEO, Palo Alt, CA. 2012. Available at http://www.hcdconnect.org/toolkit/en/download

11. Kowalenko, K. Engineering for Change Needs You! The Institute. IEEE, Piscataway, NJ. February, 4, 2011. Available at http://theinstitute.ieee.org/benefits/humanitarianefforts/engineering-for-change-needs-you 762

12. Engineering for Change. 2013. Available at https:/www.engineeringforchange.org/

13. Engineers Without Borders Canada. Reports: Successes and Failures. Engineers Without Borders Canada, Toronto, ON. Available at http:/www.ewb.ca/reports/

14. Engineers Without Borders Canada. Admitting Failure. Engineers Without Borders Canada, Toronto, ON. Available at http://www.admittingfailure.com/

15. Massachusetts Institute of Technology (MIT). D-Lab. Massachusetts Institute of Technology (MIT), Cambridge, MA. Available at http://d-lab.mit.edu/

16. Worcester Polytechnic Institute (WPI). Undergraduate Catalog: Interdisciplinary. Worcester Polytechnic Institute, Worcester, MA. Available at https://www.wpi.edu/academics/catalogs/ugrad/idcourses.html

17. Mehta, K., Brannon, M. L., Zappe, S., Colledge, T., and Zhao, Y. eplum Model of Student Engagement: Expanding Non-Travel Based Global Awareness, Multi-Disciplinary 
Teamwork and Entrepreneurial Mindset Development. Proceedings of the 2010 ASEE Annual Conference and Exposition, Louisville, KY, June 20-23, 2010.

18. Eger, C., Schreier, C., and Pinnell, M. The Engineers in Technical, Humanitarian Opportunities of Service-Learning (ETHOS) program at the University of Dayton as an Integrated Service-Learning Program Model. Proceedings of the 2006 ASEE Annual Conference and Exposition, Chicago IL, June 18-21, 2006.

19. Swan, C., Duffy, J., Paterson, K., Bielefeldt, A. R., and Pierrakos, O. The EFELTS Project Engineering Faculty Engagement in Learning Through Service. Proceedings of the 2011 ASEE Annual Conference and Exposition, Vancouver, Canada, June 26-29, 2011.

20. Coyle, E. J., Jamieson, L. H., and Oakes, W. C. 2005 Bernard M. Gordon Prize Lecture: Integrating Engineering Education and Community Service: Themes for the Future of Engineering Education. Journal of Engineering Education, 2006. 95(1), 7-11.

21. Engineers Without Borders (EWB). Engineers Without Borders - USA, Strategic Plan, March 2010. Engineers Without Borders (EWB), Boulder, CO. 2010. Available at http://www.ewb-usa.org/theme/library/about-ewb-usa/ewb-usa-strategic-plan-2010.pdf

22. Mohtar, R. H., and Dare, A. E. Global Design Team: A Global Service-Learning Experience. International Journal of Engineering Education, 2012. 28(1): 169-182.

23. Jesiek, B. Resources: Global Engineering Design Symposium (GEDS) 2012. Global Engineering Program (GEP), Purdue University, West Lafayette, IN. 2012. Available at http://globalhub.org/resources/5171

24. Gunther, G., and Memon, M. A. International Development Pitfalls and Successes: Five Case Studies from Tanzania. Livestock Research for Rural Development, 2009. 21(10). Available at http://www.lrrd.org/lrrd21/10/gunt21166.htm

25. Sharp, L. Steel Axes for Stone-Age Australians. Human Organization, 1952. 11(2): 17-22.

26. Carlson, J. The Stranger's Eyes. Notes on Anthropology and Intercultural Community Work, 1995. 20: 34-38. Available at http://www01.sil.org/anthro/articles/thestrangerseyes.htm

27. Rogers, E. M., and Steinfatt, T. M. Intercultural Communication. Waveland Press, Inc., Prospect Heights, IL. 1999.

28. Reuters. Kenya's Turkana Learns from Failed Fish Project. Epoch Times (A4). April 6, 2006. Available at http://www.daikynguyen.com/eet/print_archive/canada/toronto/2006/04Apr/06/A_4.pdf

29. Hossain, S.M., Duffield, A., and Taylor, A. An Evaluation of the Impact of a US\$60 Million Nutrition Programme in Bangladesh. Health, Policy and Planning, 2005. 20(1): 35-40.

30. Bailey, S. Flawed Aid Program Funded Newspaper That Most Afghans Couldn't Read: Audit. Free Dominion. March 6, 2007. Available at http://www.freedominion.ca/phpBB2/viewtopic.php?nomobile=1\&f=11\&t=77007

31. Stein, E. A. "Sanitary Makeshifts" and the Perpetuation of Health Stratification in Indonesia. In Hahn, R. A., and Inborn, M. (Ed.), Anthropology in Public Health (541-565). Oxford University Press, Oxford, UK. 2009.

32. Carroll, R. Broken Pumps, Dashed Hopes. The Guardian, December 2, 2002. Available at http://www.guardian.co.uk/environment/2002/dec/02/water.christmasappeal.

33. Sheppard, S., Macatangay, K., Colby, A., and Sullivan, W. M. Educating Engineers: Designing for the Future of the Field. Jossey-Bass, San Francisco, CA. 2009.

34. Women In Engineering Program (WIEP). Enrollment of Women in Engineering Hits a New Purdue Record. Purdue University, West Lafayette, IN. 2012. Available at 
https://engineering.purdue.edu/WIEP/Spotlights/enrollment-of-women-in-engineering-hitsa-new-purdue-record

35. Center of Inquiry in the Liberal Arts at Wabash College. Political and Social Involvement Scale. Wabash College, Crawfodsville, IN. 2009. Available at

http://www.liberalarts.wabash.edu/storage/assessmentinstruments/Political_Social_Involve ment_Scale.doc

36. Spinosa, H., Sharkness, J., Pryor, J. H., and Lui, A. Findings From the 2007 Administration of the College Senior Survey (CSS): National Aggregates. University of California, Los Angeles, Los Angeles, CA. 2008. Available at http://www.heri.ucla.edu/cssPublications.php

37. Higher Education Research Institute. Spiritual Changes in Students During the Undergraduate Years. Higher Education Research Institute, University of California, Los Angeles, Los Angeles, CA. 2007. Available at http://spirituality.ucla.edu/docs/news/report_backup_dec07release_12.18.07.pdf

38. Van Dyne, L., Ang, S., and Koh, C. Development and Validation of the CQS. In Ang, S., and Van Dyne, L. (Eds.), Handbook of Cultural Intelligence: Theory, Measurement, and Applications (16-38). M. E. Sharpe, Inc., Armonk, NY. 2008. 